\title{
Prevalence, antimicrobial resistance, and molecular characterization of methicillin-resistant Staphylococcus aureus from bulk tank milk of dairy herds
}

\author{
K. Kreausukon, ${ }^{\star}$ A. Fetsch, ${ }^{\star}$ B. Kraushaar, ${ }^{\star}$ K. Alt, ${ }^{*}$ K. Müller,† V. Krömker,‡ K.-H. Zessin,§ \\ A. Käsbohrer, ${ }^{*}$ and B.-A. Tenhagen ${ }^{* 1}$ \\ *Department Biological Safety, Federal Institute for Risk Assessment (BfR), 12277 Berlin, Germany \\ †Ruminant and Swine Clinic, Faculty of Veterinary Medicine, Free University of Berlin, 14163 Berlin, Germany \\ †Faculty II - Mechanical and Bioprocess Engineering, University of Applied Sciences, 30453 Hannover, Germany \\ $\S$ Department of International Animal Health, Faculty of Veterinary Medicine, Free University of Berlin, 14163 Berlin, Germany
}

\begin{abstract}
It was the objective of the study to estimate the prevalence of methicillin-resistant Staphylococcus aureus (MRSA) in bulk tank milk from German dairy herds and to characterize isolates from bulk tank milk with respect to their Staph. aureus protein A (spa) and staphylococcal cassette chromosome mec (SCCmec) type, their phenotypic antimicrobial resistance and resistance- resp. virulence-associated genes using broth microdilution and a microarray for Staph. aureus. Bulk tank milk samples $(25 \mathrm{~mL})$ were tested for MRSA using a 2-step selective enrichment protocol. Presumptive MRSA were confirmed by PCR. Thirty-six isolates collected from bulk tank milk of dairy herds in 2009 and 2010 were included in the characterization. All isolates displayed spa-types assigned to the clonal complex CC398. Based on the epidemiological cut-off values for the interpretation of minimum inhibitory concentrations isolates were resistant to tetracycline $(100 \%)$, clindamycin (58\%), erythromycin (52\%), quinupristin/ dalfopristin (36\%), and kanamycin (27\%). Isolates did not carry genes associated with typical virulence factors for Staph. aureus such as the Panton-Valentine leukocidin. However, they did carry hemolysin genes. Livestock-associated MRSA of CC398 does occur in German dairy herds and the strains have similar properties as described for strains from pigs.
\end{abstract}

Key words: dairy cow, Staphylococcus aureus, methicillin, antimicrobial resistance

\section{INTRODUCTION}

Methicillin-resistant Staphylococcus aureus (MRSA) have been identified as an emerging pathogen in live-

Received November 27, 2011.

Accepted April 6, 2012.

${ }^{1}$ Corresponding author: Bernd-Alois.Tenhagen@bfr.bund.de stock animals that is readily transferable to humans in contact with livestock. Methicillin-resistant Staph. aureus have also been identified as a mastitis pathogen in dairy cows that can be isolated from bulk tank milk (Spohr et al., 2011). So far, limited information is available on the prevalence of MRSA in dairy herds in Germany and other countries. Reports on MRSA in dairy herds are focused either on clinical cases or on within-herd prevalence of MRSA (Fessler et al., 2010; Vanderhaeghen et al., 2010; Spohr et al., 2011). One study, conducted in a small region of Germany, found a prevalence of $2.2 \%$ in 180 bulk tank milk samples (Friedrich et al., 2011). One study from the United States on MRSA in bulk tank milk did not find any positive bulk tank milk samples without using selective enrichment and with an inoculum size of $0.1 \mathrm{~mL}$. However, it has been shown that enrichment substantially increases the sensitivity of selective testing for MRSA and most of the work done on livestock-associated MRSA (laMRSA) in Europe has been done using selective enrichment. A study from Minnesota using enrichment found MRSA in $4 \%(2 / 50)$ of dairy herds (Haran et al., 2012).

Some more studies reported on features of MRSA in bulk tank milk. However, they mostly reported on a few isolates (Haran et al., 2012) or did not clarify whether copy strains were tested, because farms were studied repeatedly (Vyletělová et al., 2011).

In dairy cattle, the presence of MRSA has 3 aspects. One is the exposure of people working on dairy farms to the pathogen and their risk of getting colonized or infected (Juhász-Kaszanyitzky et al., 2007; Spohr et al., 2011). The second aspect is the contamination of raw milk with MRSA as a route of transmission of MRSA to people consuming raw milk or as initial contamination in the production chain of raw milk products. Consumption of raw milk is common among farmers (Oliver et al., 2009). In Germany, certified raw milk with a high hygienic standard can be purchased. Cheeses made from raw milk are also sold in Europe. The third aspect 
is animal health. Treatment of clinical mastitis cases and dry cow therapy are essential components of the 5 -point plan to combat contagious mastitis. Resistance to $\beta$ lactam antimicrobials reduces therapeutic options for Staph. aureus dramatically and may increase culling rates for Staph. aureus mastitis.

The objective of this study was to estimate the prevalence of MRSA in dairy herds in Germany using bulk tank milk samples and to characterize MRSA from bulk tank milk samples in dairy herds with respect to subtypes, antimicrobial resistance, and virulence-associated genes using a commercial microarray.

\section{MATERIALS AND METHODS}

\section{Prevalence Study}

Bulk tank milk samples from dairy herds were collected in the framework of a national monitoring program in 2009 and 2010 (Käsbohrer et al., 2011). As no prior information was available on the prevalence, sample size was calculated based on a prevalence of $50 \%$ with an accuracy of $\pm 5 \%$ at a $95 \%$ confidence level (Thrusfield, 2005). Thus, a sample size of 384 samples per year was targeted.

Samples were distributed among the different federal states (Länder) in Germany according to their dairy cow populations in herds having more than 20 dairy cows that were milked. Within the Länder, the selection of herds was supposed to be random; however, the randomization procedure was the responsibility of the Länder authorities.

Bulk tank milk samples were collected on farm and transported to the laboratory in coolers. Samples were analyzed for MRSA using a 2-step enrichment protocol. Briefly, $25 \mathrm{~mL}$ of milk was incubated for 16 to $20 \mathrm{~h}$ at $37^{\circ} \mathrm{C}$ in $225 \mathrm{~mL}$ of Mueller-Hinton broth (Oxoid, Wesel, Germany) supplemented with $6.5 \% \mathrm{NaCl}$. One milliliter was then inoculated into $9 \mathrm{~mL}$ of tryptone soy broth (TSB; Merck KGaA, Darmstadt, Germany) containing $3.5 \mathrm{mg} / \mathrm{L}$ of cefoxitin (Sigma-Aldrich Chemie, Munich, Germany) and $75 \mathrm{mg} / \mathrm{L}$ of aztreonam (Sigma-Aldrich Chemie), and incubated further for 16 to $20 \mathrm{~h}$ at $37^{\circ} \mathrm{C}$. One loopful of this suspension was plated onto a chromogenic agar selective for MRSA (Brilliance MRSA agar; Oxoid, Wesel, Germany), and incubated for $24 \mathrm{~h}$ at $37^{\circ} \mathrm{C}$. Based on colony morphology and color, presumptive MRSA colonies were subcultivated on sheep blood agar plates.

Isolates suspected to be MRSA were submitted to the National Reference Laboratory for coagulasepositive staphylococci, including Staph. aureus (NRL Staph, Berlin, Germany), for confirmation purposes and further testing. Isolates were confirmed as MRSA using a triplex PCR (Poulsen et al., 2003). Staphylococcus aureus protein A (spa) typing was performed according to Shopsin et al. (1999), and staphylococcal cassette chromosome mec (SCC mec) typing according to Zhang et al. (2005).

\section{Characterization of MRSA from Bulk Tank Milk}

Thirty-six MRSA isolates from bulk tank milk samples of dairy herds were investigated. Isolates included those collected in the framework of the national monitoring programs between January 2009 and August $2010(\mathrm{n}=20)$. Further isolates $(\mathrm{n}=5)$ were collected in a separate study in a convenience sample of 60 herds in northern Germany using the same sampling and laboratory protocol. That study was aimed at determining associations between farm-level risk factors and the prevalence of MRSA and extended-spectrum $\beta$-lactamase-producing Escherichia coli in bulk tank milk (Kreausukon, 2011). A third group of isolates $(\mathrm{n}=11)$ from bulk tank milk was submitted to the NRL Staph for diagnostic and confirmation purposes between January 2009 and August 2010. Each sample was from a different herd. Regional laboratories submit these isolates to the National Reference Laboratory as awareness of MRSA as a potential threat to udder health in cattle and to humans has risen. The regional laboratories rely on the NRL Staph for testing of antimicrobial resistance and further typing of such isolates.

Antimicrobial resistance testing was performed using the broth microdilution method according to the Clinical and Laboratory Standards Institute (CLSI, Wayne, PA) standards and custom-made microtiter plate panels (TREK Diagnostic Systems, Magellan Biosciences, West Sussex, UK). Staphylococcus aureus ATCC 25923 was used as the quality control strain. The 13 antimicrobials tested included those of relevance for veterinary treatment but also substances that are important for treatment of MRSA infections in humans. Evaluation of resistance was based on epidemiological cut-off values published by the European committee for antimicrobial susceptibility testing for MRSA and Staph. aureus (http://www.eucast.org). Antimicrobials tested and epidemiological cut offs used are displayed in Table 1.

Further molecular characterization of MRSA was done using a commercial array hybridization kit (Staphy Type kit; Alere Technologies GmbH, Jena, Germany) for DNA-based detection of 334 Staph. aureus gene sequences, corresponding to 185 distinct genes and alleles. This includes species specific markers, resistance- and virulence-associated genes of Staph. aureus. The procedures of total genomic DNA isolation and microarray analysis as well as a complete list of 
Table 1. Minimum inhibitory concentrations of 13 different antimicrobial agents for 36 isolates of methicillin-resistant Staphylococcus aureus (MRSA) from bulk tank milk samples in Germany

\begin{tabular}{|c|c|c|c|c|c|c|c|c|c|c|c|c|c|}
\hline \multirow{2}{*}{$\begin{array}{l}\text { Antimicrobial } \\
\text { agent }^{1}\end{array}$} & \multicolumn{11}{|c|}{$\mathrm{MIC}^{2}(\mu \mathrm{g} / \mathrm{mL})$} & \multicolumn{2}{|c|}{ Resistant $^{3}$} \\
\hline & 0.25 & 0.5 & 1 & 2 & 4 & 8 & 16 & 32 & 64 & 128 & 256 & No. & $\%$ \\
\hline CIP & & 28 & 5 & 2 & - & - & 1 & - & - & & & 3 & 8.3 \\
\hline CLI & 15 & 3 & - & - & - & - & 4 & 3 & 11 & & & 21 & 58.3 \\
\hline ERY & 3 & 12 & 2 & - & - & - & - & 19 & & & & 19 & 52.8 \\
\hline MUP & & & 36 & - & - & - & - & & & & & 0 & 0 \\
\hline $\mathrm{OXA}+2 \% \mathrm{NaCl}$ & & & - & - & 2 & 8 & 26 & & & & & 36 & 100 \\
\hline QUI/DAL & & 14 & 9 & 6 & 4 & 2 & 1 & & & & & 13 & 36.1 \\
\hline TET & & & - & - & - & - & - & - & 7 & 29 & & 36 & 100 \\
\hline VAN & & & & 36 & - & - & - & - & & & & 0 & 0 \\
\hline
\end{tabular}

${ }^{1} \mathrm{CHL}=$ chloramphenicol; $\mathrm{CIP}=$ ciprofloxacin; $\mathrm{CLI}=$ clindamycin; $\mathrm{ERY}=$ erythromycin; $\mathrm{KAN}=$ kanamycin; $\mathrm{MUP}=$ mupirocin; $\mathrm{OXA}=$ oxacillin; QUI/DAL = quinupristin/dalfopristin; TET = tetracycline; VAN = vancomycin; LZD = linezolid; GEN = gentamicin; SXT = sulfamethoxazole/trimethoprim.

${ }^{2}$ Dilution ranges tested are indicated by nonshaded cells. Values above the range indicate MIC values above the highest concentration in the range. Values at the lowest concentration tested indicate MIC value below or equal to the lowest concentration in the range.

${ }^{3}$ Isolates were classified as resistant after European Committee on Antimicrobial Susceptibility Testing (EUCAST, Växjö, Sweden) epidemiological cut-off value (http://www.eucast.org, black vertical lines) for MRSA or Staph. aureus (or both) valid at the time of submission.

${ }^{4}$ The MIC values of SXT (19:1) are given as trimethoprim MIC values.

targets have been published previously (Monecke et al., 2008a; Monecke et al., 2008b).

Among others, the kit detected presence of 14 genes encoding antimicrobial resistance, 20 genes associated with virulence factors (Table 2), and 22 genes encoding for enterotoxins (entA, entA-320E, entA- $\mathrm{N} 315$, ent $\mathrm{B}$, ent $\mathrm{C}$, entCM14, ent $\mathrm{D}$, ent $\mathrm{E}$, ent $\mathrm{G}$, ent $\mathrm{H}$, entI, ent $\mathrm{J}$, ent $\mathrm{K}$, ent $\mathrm{L}$, ent $\mathrm{M}$, ent $\mathrm{N}$, ent $\mathrm{N} \_1$, ent $\mathrm{O}$, ent $\mathrm{Q}$, ent $\mathrm{R}$, ent $\mathrm{U}$, and egc-cluster).

Moreover, the presence of genes encoding staphylococcal enterotoxins (ent $\mathrm{A}$, ent $\mathrm{A}-320 \mathrm{E}$, ent $\mathrm{A}-\mathrm{N} 315$, ent $\mathrm{B}$, ent $\mathrm{C}$, ent $\mathrm{CM} 14$, ent $\mathrm{D}$, ent $\mathrm{E}$, ent $\mathrm{G}$, ent $\mathrm{H}$, ent $\mathrm{I}$, ent $\mathrm{J}$, ent $\mathrm{K}$, ent $\mathrm{L}$, ent $\mathrm{M}$, ent $\mathrm{N}$, ent $\mathrm{N} \_1$, ent $\mathrm{O}$, ent $\mathrm{Q}$, ent $\mathrm{R}$, ent $\mathrm{U}$, and egc-cluster) and virulence factors, such as toxic shock syndrome toxins ( $t s t 1$ and $t s t-R F 122)$, Pantone-Valentine leukocidin (PVL), leukocidins (lukM/ lukF-P83, lukD, lukE, lukX, lukY-var1, and lukY-var2), hemolysin $\alpha(h l a)$, hemolysins $\beta$ ( $h l b$ and untruncated $h l b)$, hemolysins $\gamma(l u k \mathrm{~F}$, lukS, lukS-ST22+ST45, and $h l g \mathrm{~A})$, and hemolysin $\delta(h l d)$ were detected.

\section{Statistical Analysis}

Data were collected in Excel (Microsoft Corp., Redmond, WA) spreadsheets. Prevalence of MRSA in bulk tank milk samples was calculated as a crude prevalence based on the analyzed samples according to Thrusfield (Thrusfield, 2005). For all other calculations the number of isolates tested was taken as the denominator.

\section{RESULTS}

\section{Prevalence Study}

Overall, 635 samples of bulk tank milk from dairy herds were collected in the framework of the national monitoring in 2009 and 2010. Of these 28 (4.4\%, 95\% CI: $3.6-5.2 \%)$ were positive for MRSA. The prevalence rates were similar in $2009(14 / 338,4.1 \%, 95 \%$ CI: $3.1-5.2 \%)$ and 2010 (14/297, 4.7\%, 95\% CI: $3.5-5.9 \%)$. In both years, the targeted sample size was not fully achieved. However 11 and 12 of the 13 federal states with milk production participated, including all the big states, that produce most of the milk in Germany. States that have predominantly large herds were included as well as those with smaller herds. Therefore, results can be considered fairly representative for Germany.

\section{Characterization of MRSA from Bulk Tank Milk}

All 36 MRSA isolates from bulk tank milk samples were from spa types t011 (22 isolates, 61\%) and t034 
Table 2. Selected resistance and virulence associated genes included in the microarray that was used to characterize 36 methicillin-resistant Staphylococcus aureus strains from bulk tank milk in Germany

\begin{tabular}{|c|c|}
\hline Gene & Explanation \\
\hline \multicolumn{2}{|l|}{ Antimicrobial resistance } \\
\hline mecA & Methicillin, oxacillin, and other $\beta$-lactams, \\
\hline blaZ & $\beta$-Lactamase \\
\hline blaI & $\beta$-Lactamase repressor (regulatory protein) \\
\hline$b l a \mathrm{R}$ & $\beta$-Lactamase regulatory protein \\
\hline erm $\mathrm{A}$ erm $\mathrm{B}$, erm $\mathrm{C}$ & Macrolide, lincosamide, streptogramin \\
\hline$v g a \mathrm{~A}$ & Streptogramin \\
\hline$a a c \mathrm{~A}-a p h \mathrm{D}$ & Aminoglycoside (gentamicin, tobramycin) \\
\hline$a a d \mathrm{D}$ & Aminoglycoside (tobramycin, neomycin) \\
\hline tet $\mathrm{K}$, tet $\mathrm{M}$ & Tetracycline \\
\hline tetEfflux & Tetracycline efflux protein (putative transport protein) \\
\hline fexA & Chloramphenicol t r th \\
\hline \multicolumn{2}{|l|}{ Virulence gene } \\
\hline tst-1 & Toxic shock syndrome toxin \\
\hline tst-RF122 & Toxic shock syndrome toxin, allele from bovine strains \\
\hline$P V L$ & Pantone-Valentine leukocidin \\
\hline lukM/lukF-P83 & Bovine leukocidin \\
\hline $\operatorname{lukF}$ & Hemolysin $\gamma$, component B \\
\hline $\operatorname{lukS}$ & Hemolysin $\gamma$, component $\mathrm{C}$ \\
\hline $\operatorname{lukS-ST22+ST45}$ & Hemolysin $\gamma$, component $\mathrm{C}$, allele from ST22 and ST45 \\
\hline$h \lg A$ & Hemolysin $\gamma$, component A \\
\hline $\operatorname{lukD}$ & Leukocidin D component \\
\hline lukE & Leukocidin E component \\
\hline lukX, lukY-var1, lukY-var2 & Leukocidin/hemolysin toxin family proteins \\
\hline$h l$ & Hypothetical protein similar to hemolysin \\
\hline hla & Hemolysin $\alpha(\alpha$ toxin $)$ \\
\hline hld & Hemolysin $\delta$ (amphiphilic membrane toxin) \\
\hline hlIII & Putative hemolysin III \\
\hline hl_III_other than RF122 & Putative hemolysin III (other than RF122) \\
\hline$h l b$ & Hemolysin $\beta$ (phospholipase C) \\
\hline Untruncated $h l b$ & Hemolysin $\beta$ (phospholipase $\mathrm{C} /$ untruncated) \\
\hline
\end{tabular}

(14 isolates, 39\%), both associated with the clonal complex CC398. According to the typing method of Zhang et al. (2005), most isolates (33 isolates, 92\%) carried the SCCmec type V, whereas 2 isolates carried type III and 1 carried type IVa. However, the microarray confirmed the presence of the gene $c c r \mathrm{C}$ and the absence of ccr $\mathrm{A} 3$ and $c c r \mathrm{~B} 3$ in the 2 strains that were assigned to SCCmec type III by the typing scheme of Zhang et al. (2005). This indicates that they are rather variants of type V (Jansen et al., 2009).

\section{Antimicrobial Resistance}

Minimum inhibitory concentrations of the 36 isolates are displayed in Table 1. All isolates were resistant to oxacillin and tetracycline. Resistance to clindamycin, erythromycin, kanamycin, and quinupristin/dalfopristin was detected at high rates in 21 (58.3\%), 19 (52.8\%), 10 $(27.8 \%)$, and $13(36.1 \%)$ isolates, respectively. Resistance to ciprofloxacin was found in 3 isolates (8.3\%). Only one isolate was resistant to chloramphenicol. All isolates were susceptible to mupirocin, vancomycin, and linezolid. The most frequent patterns were resistance to tetracycline and oxacillin alone (10 isolates, 27.8\%) and in combination with resistance to erythromycin, clindamycin, and quinupristin/dalfopristin (9 isolates, $25.0 \%$ ). All other patterns were shown by 2 isolates at most.

\section{Genes Encoding for Antimicrobial Resistance}

All MRSA isolates in this study carried more than 1 of the tested antimicrobial resistance genes. Table 3 displays the number of isolates carrying the various resistance gene combinations. Eighteen different antimicrobial resistance gene patterns were identified. All isolates carried the resistance genes mecA, tet $\mathrm{M}$, and tetEfflux. All but one additionally carried the $\beta$-lactamase genes blaZ, blaI, and blaR. Otherwise, combinations showed some variability with 19 isolates $(52.8 \%)$ carrying an additional resistance gene for tetracycline $($ tet $\mathrm{K})$, erm $\mathrm{A}$, erm $\mathrm{B}$, and $\operatorname{erm} \mathrm{C}$, alone or in combination were observed in 18 isolates. The gene $v g a \mathrm{~A}$, conferring resistance to streptogramins, was observed in 5 isolates, 2 of which also carried ermC. Nine isolates carried resistance genes conferring resistance against aminoglycosides. Among those, 4 carried aadD and 5 carried $a a c \mathrm{~A}-a p h \mathrm{D}$; none of them carried both. Only 1 isolate carried fexA, conferring resistance to chloramphenicol. 
Table 3. Antimicrobial resistance genes demonstrated in 36 methicillin-resistant Staphylococcus aureus strains derived from bovine milk samples

\begin{tabular}{|c|c|c|}
\hline Gene & $\begin{array}{l}\text { No. of } \\
\text { positive } \\
\text { isolates }\end{array}$ & $\%$ \\
\hline mecA, tetM, tetEfflux, tetK & 1 & 2.8 \\
\hline mecA, blaZ, blaI, blaR, tet $\mathrm{M}$, tetEfflux & 3 & 8.3 \\
\hline mecA, blaZ, blaI, blaR, tet $\mathrm{M}$, tetEfflux, ermA & 5 & 13.9 \\
\hline mecA, blaZ, blaI, bla $\mathrm{R}$, tet $\mathrm{M}$, tetEfflux, erm $\mathrm{C}$ & 1 & 2.8 \\
\hline 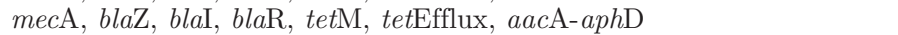 & 2 & 5.6 \\
\hline$m e c \mathrm{~A}$, blaZ, blaI, blaR, tet $\mathrm{M}$, tetEfflux, erm $\mathrm{A}$, aad $\mathrm{D}$ & 1 & 2.8 \\
\hline mecA, blaZ, blaI, blaR, tet $\mathrm{M}$, tetEfflux, erm $\mathrm{A}$, erm $\mathrm{C}$ & 1 & 2.8 \\
\hline mecA, blaZ, blaI, blaR, tet $\mathrm{M}$, tetEfflux, ermB, aad $\mathrm{D}$ & 2 & 5.6 \\
\hline mecA, blaZ, blaI, blaR, tet $\mathrm{M}$, tetEfflux, erm $\mathrm{C}$, aad $\mathrm{D}$, fex $\mathrm{A}$ & 1 & 2.8 \\
\hline mecA, blaZ, blaI, blaR, tet $\mathrm{M}$, tetEfflux, vgaA, aacA-aphD & 1 & 2.8 \\
\hline mecA, blaZ, blaI, blaR, tet $\mathrm{M}$, tetEfflux, tetK & 8 & 22.2 \\
\hline mecA, blaZ, blaI, blaR, tet $\mathrm{M}$, tetEfflux, tetK, erm $\mathrm{A}$ & 3 & 8.3 \\
\hline mecA, blaZ, blaI, blaR, tet $\mathrm{M}$, tetEfflux, tetK, erm $\mathrm{C}$ & 2 & 5.6 \\
\hline mecA, blaZ, blaI, blaR, tetM, tetEfflux, tetK, vgaA & 1 & 2.8 \\
\hline mecA, blaZ, blaI, blaR, tet $\mathrm{M}$, tetEfflux, tetK, ermA, ermB & 1 & 2.8 \\
\hline mecA, blaZ, blaI, blaR, tetM, tetEfflux, tetK, erm $\mathrm{C}$, vgaA & 1 & 2.8 \\
\hline mecA, blaZ, blaI, blaR, tet $\mathrm{M}$, tetEfflux, tetK, vgaA, aacA-aph $\mathrm{D}$ & 1 & 2.8 \\
\hline mecA, blaZ, blaI, blaR, tet $\mathrm{M}$, tetEfflux, tetK, erm $\mathrm{C}$, vgaA, aacA-aphD & 1 & 2.8 \\
\hline Total & 36 & 100 \\
\hline
\end{tabular}

\section{Genes Encoding for Enterotoxins, Toxic Shock Syndrome Toxins, Leukocidins, and Hemolysins}

All isolates tested negative for all genes encoding staphylococcal enterotoxins. In addition, none of the isolates carried the genes encoding toxic shock syndrome toxins (tst1 and tst-RF122); Pantone-Valentine leukocidin, including its bovine variant (PVL and $l u k \mathrm{M} / l u k \mathrm{~F}$ $\mathrm{P} 83$ ); other leukocidins (lukD, lukE, and lukY-var2); or hemolysin $\beta$ (hlb). In contrast, all isolates carried lukX and lukY-var1, encoding leukocidins/hemolysin toxin family proteins and the hemolysin genes hla, untruncated $h l b, h l d, h l \_I I I \_o t h e r$ than RF122, $h l$ (hypothetical protein similar to hemolysin), hIIII, (putative hemolysin III), and hemolysin $\gamma(l u k \mathrm{~F}, l u k \mathrm{~S}$, and $h l g \mathrm{~A})$.

\section{DISCUSSION}

This is the first nationwide survey on MRSA in bulk tank milk from dairy herds using standardized procedures. So far, limited information is available on the prevalence of MRSA in dairy herds. One study carried out in the United States did not identify MRSA in bulk tank milk (Virgin et al., 2009). However, that study used traditional mastitis bacteriology methods with an inoculum of $0.1 \mathrm{~mL}$, which is substantially less than the $25 \mathrm{~mL}$ used in this study. Moreover, selective enrichment is likely to increase sensitivity, as recently shown in mastitis milk samples from dairy herds in Germany (Spohr et al., 2011). Therefore, results are probably not comparable. A study from Minnesota tested bulk tank milk from herds repeatedly (Haran et al., 2012). This study used a 2-step enrichment procedure comparable to ours and found MRSA in samples from 2 of the 50 farms investigated. However, they did not report the volume included in the laboratory procedure. A study using the same detection methods as we did on samples from a small region in Southwest Germany found 4 of 180 bulk tank milk samples $(2.2 \%)$ positive for MRSA. A study in Switzerland did not find MRSA in bulk tank milk but in mastitis samples from cows (Huber et al., 2010).

Other studies were restricted either to prevalence determination in individual herds or in small groups of preselected dairy herds (Vanderhaeghen et al., 2010; Spohr et al., 2011) or to more detailed analysis of isolates from mastitis cases or bulk tank milk with no further reference to prevalence (Fessler et al., 2010; Vanderhaeghen et al., 2010; Vyletělová et al., 2011). As a consequence of scarce literature on prevalence, little is known about risk factors for the presence of MRSA in dairy herds. Presence of pigs on the farm could be considered a potential risk factor, as pigs are known to frequently harbor MRSA. In the study in southwestern Germany, the authors suspected a relation with the regional pig density, as they found most MRSA-positive herds in a county with a very high pig density (Friedrich et al., 2011). However, that county has an overall high density of farm animals. Therefore, this hypothesis needs to be tested in further studies. In a case study on 3 herds, 2 of the MRSA-positive herds did not house pigs and had no contact with pig farms (Spohr et al., 2011). 
Results of the study show that MRSA of the most frequent livestock associated spa types in pigs (Tenhagen et al., 2009; Alt et al., 2011) and turkeys (Richter et al., 2012) in Germany and Europe (EFSA, 2009) can also be found in bulk tank milk in German dairy herds. This is of concern, as MRSA of the spa types identified in the present study have been shown to be involved in clinical mastitis (Fessler et al., 2010; Huber et al., 2010), and are associated with high SCC (Spohr et al., 2011). It has been pointed out that this is a major drawback for the control of Staph. aureus mastitis, as most antimicrobials used in control programs either for therapy of clinical cases or for dry cow therapy are $\beta$-lactams (Spohr et al., 2011). As the bacteria are also resistant to several other antimicrobials, the role of therapy in the control of Staph. aureus mastitis is further reduced. Identification of infected animals, culling or separation of infected animals from uninfected, strict milking time hygiene, and postmilking teat and cluster disinfection to avoid transmission of MRSA between cows are of highest importance.

Recently, it has been pointed out that MRSA in dairy herds are not only observed as IMI, but can also be isolated from healthy calves fed whole milk and other body sites of dairy cows (Spohr et al., 2011). The importance of this colonization as a source of infection of the mammary glands has not been determined so far, although the potential role of other sources for Staph. aureus in IMI has been pointed out in the past (Hata et al., 2010).

The high prevalence of resistance genes and the low prevalence of virulence-associated genes are in line with results of previous studies on MRSA of the CC398 clonal complex in general (Argudin et al., 2011) and specifically from cases of mastitis (Fessler et al., 2010). Resistance to erythromycin, lincosamides, and gentamicin $(52.8,58.3$, and $16.7 \%)$ is of special concern, as these drugs are among the few drugs licensed for the treatment of bovine mastitis that are not based on $\beta$-lactams. Resistance rates to these drugs were similar, as reported by Fessler et al. (2010; 56.2, 56.2, and $18.8 \%$ ), for isolates from cases of clinical mastitis. Resistance to kanamycin, another drug licensed for the treatment of bovine mastitis was also frequent (27.8\%). Moreover, the resistance genes involved were also similar to the genes described for mastitis strains (Fessler et al., 2010) and other strains of MRSA from various origins of the same spa types (Argudin et al., 2011).

The great similarities in the antimicrobial resistance patterns and resistance and virulence genes of the bulk tank milk strains in comparison with the strains from clinical mastitis and from other nonbovine sources point to the likelihood of horizontal spread of this type of MRSA between animal species and production type, which has already been reported (Catry et al., 2010). The reason for the ability to spread rapidly in the different populations calls for further investigation into the adaptive mechanisms that it uses.

With respect to the zoonotic potential of this type of MRSA, susceptibility to major antimicrobials used in the treatment of MRSA (mupirocin, vancomycin, and linezolid) and the absence of major virulence genes in the isolates indicates that severe courses of infections in humans are not very likely and several options still exist for the antimicrobial treatment of these infections. This is in line with an international report on the severity of human infections with laMRSA. That report stated that the clinical course of infections with laMRSA is, overall, less severe compared with infections with other types of MRSA (van Cleef et al., 2011). However, people working on dairy farms have to be considered as being at an increased risk for colonization (Spohr et al., 2011). Their awareness of the issue should be raised and health care facilities should consider not only people working on pig and veal farms, but also those from dairy farms as a risk group for carriage of MRSA.

Methicillin-resistant Staph. aureus in milk are of minor importance as a food safety issue, as milk is almost always heat treated before consumption. In fact, heat treatment of milk sold for consumption is mandatory, with few exceptions in Germany. However, these exceptions and on-farm consumption of raw milk that is widely practiced by farmers and their families (Oliver et al., 2009) might expose people to MRSA. In comparison with contact with colonized or infected animals, a well-described transmission route for people working in pig and veal farms, the exposure via consumption of milk is likely to be less important, as Staph. aureus is not an enteric pathogen. However, information on the number of bacteria required for an oral infection is not available. Therefore, further research on this issue and consistent heat treatment of milk before consumption seem advisable.

\section{ACKNOWLEDGMENTS}

The authors gratefully acknowledge the support of the veterinary officials and regional authorities as well as the staff of the Ruminant and Swine Clinic (Berlin, Germany) and the technicians at the Federal Institute for Risk Assessment (BfR, Berlin, Germany). K. Kreausukon received a grant from the Free University of Berlin (Berlin, Germany). This study has been partially supported by a grant from the Bundesministerium für Bildung und Forschung, "MedVet-Staph" (01KI1014C). 


\section{REFERENCES}

Alt, K., A. Fetsch, A. Schroeter, B. Guerra, J. A. Hammerl, S. Hertwig, N. Senkov, A. Geinets, C. Mueller-Graf, J. Braeunig, A. Kaesbohrer, B. Appel, A. Hensel, and B.-A. Tenhagen. 2011. Factors associated with the occurrence of MRSA CC398 in herds of fattening pigs in Germany. BMC Vet. Res. 7:69.

Argudín, M. A., B.-A. Tenhagen, A. Fetsch, J. Sachsenröder, A. Käsbohrer, A. Schroeter, J. A. Hammerl, S. Hertwig, R. Helmuth, J. Bräunig, M. C. Mendoza, B. Appel, M. R. Rodicio, and B. Guerra. 2011. Virulence and resistance determinants of German Staphylococcus aureus ST398 isolates from non-human sources. Appl. Environ. Microbiol. 77:3052-3060.

Catry, B., E. van Duijkernen, M. C. Pomba, C. Greko, M. A. Moreno, S. Pyörälä, M. Ružauskas, P. Sanders, E. J. Threlfall, F. Ungemach, K. Törneke, C. Muñoz-Madero, and J. Torren-Edo. 2010. Reflection paper on MRSA in food-producing and companion animals: Epidemiology and control options for human and animal health. Epidemiol. Infect. 138:626-644.

EFSA (European Food Safety Authority). 2009. Analysis of the baseline survey on the prevalence of methicillin-resistant Staphylococcus aureus (MRSA) in holdings with breeding pigs, in the EU, 2008-Part A: MRSA prevalence estimates. EFSA J. 7:1376. [82 pp.]

Fessler, A., C. Scott, K. Kadlec, R. Ehricht, S. Monecke, and S. Schwarz. 2010. Characterization of methicillin-resistant Staphylococcus aureus ST398 from cases of bovine mastitis. J. Antimicrob. Chemother. 65:619-625.

Friedrich, A., J. Rau, S. Hörlacher, and M. Spohr. 2011. Prevalence of methicillin-resistant Staphylococcus aureus (MRSA) in milk from dairy farms in Northern Württemberg. Tierarztl. Umsch. 66:195-200.

Haran, K. P., S. M. Godden, D. Boxrud, S. Jawahir, J. B. Bender, and S. Sreevatsan. 2012. Prevalence and Characterization of Staphylococcus aureus, including methicillin-resistant Staphylococcus aureus, isolated from bulk tank milk from Minnesota dairy farms. J. Clin. Microbiol. 50:688-695.

Hata, E., H. Kobayashi, H. Nakajima, Y. Shimizu, and M. Eguchi. 2010. Epidemiological analysis of Staphylococcus aureus isolated from cows and the environment of a dairy farm in Japan. J. Vet. Med. Sci. 72:647-652.

Huber, H., S. Koller, N. Giezendanner, R. Stephan, and C. Zweifel. 2010. Prevalence and characteristics of meticillin-resistant Staphylococcus aureus in humans in contact with farm animals, in livestock, and in food of animal origin, Switzerland, 2009. Euro. Surveill. $15:$ pii $=19542$

Jansen, M. D., A. T. Box, and A. C. Fluit. 2009. SCCmec typing in methicillin-resistant Staphylococcus aureus strains of animal origin. Emerg. Infect. Dis. 15:136-137.

Juhász-Kaszanyitzky, E., S. Jánosi, P. Somogyi, A. Dán, L. vanderGraaf van Bloois, E. van Duijkeren, and J. Wagenaar. 2007. MRSA transmission between cows and humans. Emerg. Infect. Dis. 13:630-632.

Käsbohrer, A., K. Alt, and B.-A. Tenhagen. 2011. Zoonosen-Stichprobenplan 2009. Pages 27-31 in Erreger von Zoonosen in Deutschland 2009. M. Hartung and A. Käsbohrer, ed. Federal Institute for Risk Assessment, Berlin, Germany, http://www.bfr.bund.de/ cm/350/erreger_von_zoonosen_in_deutschland_im_jahr_2009. pdf.

Kreausukon, K. 2011. Usage of antimicrobials on 60 dairy farms in Northern Germany and characterization of methicillin-resistant Staphylococcus aureus (MRSA) and extended spectrum betalactamases producing Escherichia coli (ESBLs-producing E. coli) isolated from bulk tank milk samples. PhD Diss. Freie Universität Berlin, Berlin, Germany.

Monecke, S., L. Jatzwauk, S. Weber, P. Slickers, and R. Ehricht. 2008a. DNA microarray-based genotyping of methicillin-resistant Staphylococcus aureus strains from Eastern Saxony. Clin. Microbiol. Infect. 14:534-545.

Monecke, S., P. Slickers, and R. Ehricht. 2008b. Assignment of Staphylococcus aureus isolates to clonal complexes based on microarray analysis and pattern recognition. FEMS Immunol. Med. Microbiol. 53:237-251.

Oliver, S. P., K. J. Boor, S. C. Murphy, and S. E. Murinda. 2009. Food safety hazards associated with consumption of raw milk. Foodborne Pathog. Dis. 6:793-806.

Poulsen, A. B., R. Skov, and L. V. Pallesen. 2003. Detection of methicillin resistance in coagulase-negative staphylococci and in staphylococci directly from simulated blood cultures using the EVIGENE MRSA detection kit. J. Antimicrob. Chemother. 51:419-421.

Richter, A., R. Sting, C. Popp, J. Rau, B. A. Tenhagen, B. Guerra, H M. Hafez, and A. Fetsch. 2012. Prevalence of types of methicillinresistant Staphylococcus aureus in turkey flocks and personnel attending the animals. Epidemiol. Infect. Feb 10:1-10. [Epub ahead of print].

Shopsin, B., M. Gomez, S. O. Montgomery, D. H. Smith, M. Waddington, D. E. Dodge, D. A. Bost, M. Riehman, S. Naidich, and B. N. Kreiswirth. 1999. Evaluation of protein A gene polymorphic region DNA sequencing for typing of Staphylococcus aureus strains. J. Clin. Microbiol. 37:3556-3563.

Spohr, M., J. Rau, A. Friedrich, G. Klittich, A. Fetsch, B. Guerra, J. A. Hammerl, and B. A. Tenhagen. 2011. Methicillin-resistant Staphylococcus aureus (MRSA) in three dairy herds in Southwest Germany. Zoonoses Public Health 58:252-261.

Tenhagen, B.-A., A. Fetsch, B. Stührenberg, G. Schleuter, B. Guerra, J. A. Hammerl, S. Hertwig, J. Kowall, U. Kämpe, J. Bräunig, A Schroeter, A. Käsbohrer, and B. Appel. 2009. Prevalence of MRSA types in slaughter pigs in different German abattoirs. Vet. Rec. 165:589-593.

Thrusfield, M. 2005. Veterinary Epidemiology. 3rd ed. Blackwell Science Ltd., Oxford, UK.

van Cleef, B. A. G. L. , D. L. Monnet, A. Voss, K. Krziwanek, F. Allerberger, M. Struelens, H. Zemlickova, R. L. Skov, J. Vuopio-Varkila, C. Cuny, A. W. Friedrich, I. Spiliopoulou, J. Pászti, H. Hardardottir, A. Rossney, A. Pan, A. Pantosti, M. Borg, H. Grundmann, M. Mueller-Premru, B. Olsson-Liljequist, A. Widmer, S. Harbarth, A. Schweiger, S. Unal, and J. A. J. W. Kluytmans. 2011. Livestockassociated methicillin-resistant Staphylococcus aureus in humans, Europe. Emerg. Infect. Dis. 17:502-505.

Vanderhaeghen, W., T. Cerpentier, C. Adriaensen, J. Vicca, K. Hermans, and P. Butaye. 2010. Methicillin-resistant Staphylococcus aureus (MRSA) ST398 associated with clinical and subclinical mastitis in Belgian cows. Vet. Microbiol. 144:166-171.

Virgin, J. E., T. M. Van Slyke, J. E. Lombard, and R. N. Zadoks. 2009. Short communication: Methicillin-resistant Staphylococcus aureus detection in US bulk tank milk. J. Dairy Sci. 92:4988-4991.

Vyletělová, M., H. Vlková, and I. Manga. 2011. Occurrence and characteristics of methicillin resistant Staphylococcus aureus and methicillin resistant coagulase-negative staphylococci in raw milk manufacturing. Czech J. Food Sci. 29:S11-S16.

Zhang, K., J.-A. McClure, S. Elsayed, T. Louie, and J. M. Conly. 2005. Novel multiplex PCR assay for characterization and concomitant subtyping of staphylococcal cassette chromosome mec types I to V in methicillin-resistant Staphylococcus aureus. J. Clin. Microbiol. 43:5026-5033. 